\title{
THE SURVEY OF PERCEIVED ORGANISATIONAL SUPPORT: WHICH MEASURE SHOULD WE USE?
}

\section{Authors:}

Jody A. Worley ${ }^{1}$

Dale R. Fuqua ${ }^{2}$

Chan M. Hellman ${ }^{1}$

\section{Affiliations: \\ ${ }^{1}$ Department of Human \\ Relations, University of}

Oklahoma, USA

${ }^{2}$ School of Educational Studies, Oklahoma State University, USA

Correspondence to: Jody A. Worley

e-mail:

jworley@ou.edu

\section{Postal address:}

Department of Human Relations, University of Oklahoma, 4521 East 41st Street, Tulsa, Oklahoma 74135, USA

Keywords: organisational support; Survey of Perceived Organisational Support (SPOS); factor structure; employee perceptions; organisational behaviour

\section{Dates:}

Received: 06 Oct. 2008 Accepted: 19 May 2009 Published: 24 July 2009

How to cite this article: Worley, J.A., Fuqua, D.R., \& Hellman, C.M. (2009). The survey of perceived organisational support: Which measure should we use? SA Journal of Industrial Psychology/SA Tydskrif vir Bedryfsielkunde, 35(1), Art. \#754, 5 pages. DOI:10.4102/ sajip.v35i1.754

This article is available at:

http://www.sajip.co.za

(c) 2009. The Authors. Licensee: OpenJournals Publishing. This work is licensed under the Creative Commons Attribution License.

\section{ABSTRACT}

The psychometric properties of the original 36-item Survey of Perceived Organisational Support (SPOS) was examined along with a variety of shorter versions currently in use (16 items, eight items and three items). Factor analysis of the original SPOS measure is supportive of the original finding that the SPOS is unidimensional. Correlations among factor scores and SPOS scale scores suggest that either the eight-item or 16-item version would be just as effective as the 36 -item version but even more efficient. Convergent validity results also indicate similar proportions of variance in versions of SPOS scores accounted for by selected organisational variables.

\section{INTRODUCTION}

Since its emergence two decades ago, perceived organisational support (POS) continues to enjoy prominence as an important construct in understanding organisational behaviour. POS has been used to better understand the organisational commitment process within the framework of exchange theory (Eisenberger, Huntington, Hutchison \& Sowa, 1986). Thus far, research has primarily targeted organisational outcomes such as commitment, turnover, global job satisfaction and performance (Eisenberger, Rhoades \& Cameron, 1999; Rhoades, Eisenberger \& Armeli, 2001; Settoon, Bennett \& Liden, 1996; Shore \& Wayne, 1993; Wayne, Shore \& Liden, 1997). Eisenberger (2009) lists more than 275 published studies that have included the POS measure. Meta-analytic results (Rhoades \& Eisenberger, 2002) have shown several antecedents to POS, including (a) perceptions of procedural or distributive justice and organisational politics (Cropanzano, Howes, Grandy \& Toth, 1997; Moorman, Blakely \& Niehoff, 1998), (b) job conditions such as autonomy and pay (Eisenberger et al., 1999), (c) supervisor support (Settoon et al., 1996; Wayne et al., 1997) and (d) human resource (HR) practices such as reward systems, decisionmaking opportunities and growth opportunities (Allen, Shore \& Griffeth, 2003; Wayne et al., 1997).

POS reflects the general belief held by an employee that the organisation values his or her continued membership and is generally concerned about his or her well-being (Aselage \& Eisenberger, 2003; Eisenberger et al., 1986; Rhoades et al., 2001). This operationalisation of POS denotes the possibility of two theoretically distinct components of POS. First, organisational support is a global belief that the organisation recognises and values employee contribution as reflected in tangible resources such as pay, rank, job enrichment, rewards or other forms of compensation and benefits (Eisenberger et al., 1986; Levinson, 1965; Sinclair \& Tetrick, 1995; Wayne et al., 1997). This notion of organisational support suggests that perceived support would raise an employee's expectancy that the organisation would reward greater effort toward meeting organisational goals. The second component of organisational support is the belief that the organisation is concerned about the socioemotional well-being of employees. This aspect of organisational support reflects employee perceptions with regard to organisational policies and practices pertaining to time away from work for personal circumstances or family care.

In its original form, the Survey of Perceived Organisational Support (SPOS) consisted of 36 items and was argued to reflect a unidimensional construct. Given the benefits of considering POS in organisational research and its dimensionality it is not surprising that in the interest of time and space researchers often use fewer items. Indeed, a variety of shorter versions (16 items, eight items and three items) are being used. While the construct of POS is clearly helpful toward understanding the employee-organisational relationship, several measurement issues need to be resolved. The purpose of this research was to evaluate the psychometric properties of the various forms of the SPOS. Specifically, the underlying structure of the original 36-item SPOS was re-examined in an effort to further establish dimensionality. Furthermore, reliability analyses for the four versions of the SPOS were conducted as a means to compare the internal consistency across forms.

\section{Factor structure of POS}

In the original scale development study of SPOS conducted by Eisenberger et al. (1986), a principal components analysis (PCA) of individual responses to the original 36 items combined across nine organisations ( $n=361$ indicated a single factor accounting for $48.3 \%$ of the total variance, with an interitem reliability (Cronbach's alpha) of 0.97, which is not surprising given the number of items. Eisenberger et al. (1986) included a second study using 17 SPOS items with the highest structure coefficients. The reduced number of SPOS items was subjected to factor analysis. While the criterion used to determine the number of factors was not reported, the dominant factor for the 17 SPOS items accounted for $50 \%$ of the total variance. Eisenberger's conclusion that the POS construct is unidimensional raises two questions: Firstly, what accounts for the other $50 \%$ of the total variance? Given the use of PCA, it is not surprising that the first component accounts for a large amount of variance relative to the subsequent components.

Secondly, the interpretation of Eisenberger's conclusion for dimensionality is further complicated because the criterion used to determine the number of components to retain was not reported. Nevertheless, Eisenberger et al. (1986) did subject the items to a second factor analysis with varimax rotation, using Kaiser normalisation with a two-factor solution, and reported that all 36 items loaded higher on the first 
single factor than on the possible second factor. Moreover, the smallest loading on this single factor was larger than the largest loading on the possible second factor.

Examining the dimensionality of SPOS, several studies have used confirmatory factor analysis (CFA) with maximum likelihood estimation to compare nested covariance models for the total variance explained and overall model fit (Eisenberger, Armeli, Rexwinkel, Lynch \& Rhoades, 2001; Eisenberger, Cummings, Armeli \& Lynch, 1997; Hutchison, 1997; Rhoades et al., 2001; Settoon et al., 1996; Shore \& Tetrick, 1991). All of the studies that performed a CFA to confirm the underlying structure of the SPOS used a reduced number of the POS items, presumably based on the acceptance that the original set of 36 POS items formed a unidimensional scale. Shore and Tetrick (1991) conducted the only CFA study that included the 17 items that Eisenberger et al. (1986) recommended as a shorter version of the SPOS measure. Again, that recommendation was to use items with the highest loadings. All of the studies other than that of Shore and Tetrick (1991) used fewer than 17 of the original SPOS items. The majority of the studies did not indicate exactly which of the original items were used to develop the various shorter forms ranging from three items (Eisenberger, Stinglhamber, Vandenberghe, Sucharski \& Rhoades, 2002) to the 17 used by Shore and Tetrick (1991). The presumption is that items with the highest loadings were selected from Eisenberger et al. (1986). Results from each of the studies consistently indicated a unidimensional POS construct. The limitation remains that none of the studies using the POS variable used all 36 of the SPOS items. Moreover, the items used were selected from the results of the original PCA that fit two theoretically distinct components of the construct on a single component that accounted for only $48.3 \%$ of the total variance.

In the two decades since the development of the POS survey, the study by Self, Holt and Schaninger (2005) has been the only study to report the use of principal axis factor (PAF) analysis using oblique rotation to evaluate the factor structure of the POS items. Self et al. (2005) included 16 of the original 36 POS items in their study. In addition to the POS items, Self et al. (2005) developed 'work group support' items by substituting the word 'organisation' with 'work group' in each item. After subjecting the combined group of items from both measures to the PAF analysis using oblique rotation, the researchers retained factors with eigenvalues greater than 1.0, which was consistent with their interpretation of the observed scree plot. Moreover, none of the cross-loadings was greater than 0.25 on the unintended factor. Self et al. (2005) also conducted a followup CFA to evaluate the underlying structure of the two 16-item measures using simultaneous estimation procedures for the variance-covariance matrixes. Specifically, they compared the overall fit of a single-factor versus a two-factor latent model to the responses (i.e. data) generated from the 32 items. Several reported that fit indexes met the conventional criterion for adequate model fit for the two-factor model.

The SPOS has been shown to be distinct from affective and continuance commitment (Eisenberger, Fasolo \& DavisLaMastro, 1990; Hutchison, 1997; Rhoades et al., 2001; Settoon et al., 1996; Shore \& Tetrick, 1991; Shore \& Wayne, 1993), effortreward expectancies (Eisenberger et al., 1990), perceived supervisory support (Hutchison, 1997; Kottke \& Sharafinski, 1988), perceived team support (Bishop, Scott \& Burroughs, 2000), work group support (Self et al., 2005) and leader-member exchange (Settoon et al., 1996; Wayne et al., 1997). Again support for both the unidimensional nature of the SPOS and its validity estimates relative to other important constructs allows organisational support to enjoy a growing place in organisational research.

The development of the SPOS began as an attempt to better understand organisational commitment processes and various aspects of commitment, such as absenteeism and turnover. Results from the initial principal components analysis indicated that the 36-item measure is reflective of a unidimensional POS construct. Several subsequent studies have examined the factor structure of the SPOS using a reduced number of items. However, not one study has attempted to examine the underlying factor structure of the complete SPOS (including all 36 original items) using principal axis factor analysis with oblique rotation. This approach would allow the linear combinations of items and resulting factors to be correlated, thus providing a greater likelihood of revealing the two theoretically distinct components of POS originally suggested by Eisenberger et al. (1986).

\section{Research approach}

\section{RESEARCH DESIGN}

The current study design involved subjecting all 36 of the individual POS item responses to a principal axis factor analysis followed by oblique rotation. This approach allows for an improvement in the interpretation of the factor structure, which addresses the first research question in this study. The use of orthogonal rotation as in the original study by Eisenberger et al. (1986) assumes that components or factors are uncorrelated. Many researchers would prefer to either test this assumption or to allow some minor correlations among factors. Because the conceptual development of POS considers two facets, a reasonable analytic strategy would allow for some correlation. Therefore, an oblique rotation method was used for interpreting the structure underlying the POS survey.

The study design also included an evaluation of the internal consistency reliability for four versions of the POS measure. The original version of the measure included 36 items, most of which are rarely used in practice. Most published studies that have included a measure of POS have used a shortened form that includes only about one-half of the original items. An even shorter version includes only eight items, and at least one study has reported a three-item measure of POS. Reliability analyses were conducted for each of these versions of POS.

\section{Participants and procedure}

The participants in this study were full-time employees from a large, metropolitan community college located in the Midwestern United States. A complete list $(\mathrm{N}=868)$ of prospective participants was obtained from the human resources office. Prospective participants were predominately white (82\%), their average age was 46 and their average length of employment was 12 years. Approximately $58 \%$ of prospective participants were nonacademic staff, while $32 \%$ were full-time faculty members and $10 \%$ were administrators. Participation in this study was voluntary, and participants were not compensated.

A simple random sample of all full-time employees was used to generate a sample of 450 full-time employees. The sample included faculty, staff and administrators who were invited to participate during the autumn of 2005. These employees were emailed an invitation to participate and an informed consent form for the web-based survey. Participants did not provide any information that could be used to identify individual respondents. Two follow-up email messages were sent to encourage completion of the survey by non-respondents. A total of 283 surveys were returned, but 17 records were identified as having substantial portions of the data missing. Therefore, a total of 266 completed surveys were returned, resulting in a response rate of $59.1 \%$. The average age of the respondents was 48 years old. The average length of employment was 12 years. The employment positions represented within the respondent sample were similar to those of the total employee population with $43 \%$ nonacademic staff, 36\% full-time faculty members, $12 \%$ administrators while $9 \%$ did not report their position. 


\section{Measuring instruments/methods of data gathering}

In addition to the measure of POS, the analysis included three known correlates of POS as a means to assess the validity of each of the different POS versions (36 items, 16 items, eight items and three items). The known correlates are variables commonly used in organisational research studies that also include a measure of POS. Responses to each of the measures were obtained by using a Likert-type response format with response options ranging from $1=$ 'strongly disagree' to $7=$ 'strongly agree'.

The POS measure included all 36 items from the original SPOS (Eisenberger et al., 1986). A reliability and item analysis of the scores obtained in the original study indicated acceptable internal consistency (Cronbach's alpha) of 0.97 , with item-total correlations ranging from 0.42 to 0.83 . The mean and median item-total correlations were 0.67 and 0.66 , respectively. In the original study, Eisenberger et al. (1986) used principal components analysis and reported that every one of the 36 items showed a strong loading on a single component accounting for $48.3 \%$ of the total variance with a possible second component accounting for $4.4 \%$ of the total variance.

In addition to the original 36 -item instrument, a 17 -item version of the POS survey was introduced by Eisenberger et al. (1986) by selecting high-loading items from the 36-item set. Later, 16item and eight-item versions of the scale were also introduced by selecting high-loading items from the original survey of perceived organisational support. The eight-item scale follows the recommendation of Rhoades and Eisenberger (2002, p. 699): 'Because the original scale is unidimensional and has high internal reliability, the use of shorter versions does not appear problematic.' Although Eisenberger et al. (1986) do not refer to an eight-item version of the instrument, information about assessing POS available in Eisenberger (2009) requests that the 1986 article be referenced if the eight-item version is used. A three-item version of the POS measure has also been adapted from the original 36 items (Eisenberger et al., 2002). The internal consistency reliability (coefficient alpha) for the three-item measure was reported as $\alpha=0.75$ (Eisenberger et al., 2002).

Affective commitment in an organisational context refers to the emotional link between the individual and the organisation. Affective commitment was measured using the eight-item scale developed by Allen and Meyer (1990). The internal consistency reliability (Cronbach's alpha) for the affective commitment scores reported in Allen and Meyer (1990) was 0.87. Sample items for the affective commitment measure include statements such as 'I would be very happy to spend the rest of my career with this organisation' and 'I enjoy discussing my organisation with people outside it.'

Organisational participation is a measure that refers to the level of desired organisational contribution and perceived involvement in decision making. Employees are asked how often their supervisor asks for their involvement and how often the employee wants to be asked by the supervisor for his or her involvement. This particular measure of organisational participation includes 27 items developed by Kahnweiler and Thompson (2000). The internal consistency reliability (coefficient alpha) for responses to the 27-item measure in the current study was $\alpha=0.90$.

Organisational communication was measured using a sixitem scale that examines the degree to which communication flows freely between colleagues and between supervisors and subordinates (Seashore, Lawler, Mirvis \& Camman, 1983, p. 101). High scores indicate a favourable perception of open communication.
TABLE 1

Variance associated with the initial factors $(N=266)$

\begin{tabular}{lrrrr}
\hline MEASURE & FACTOR & EIGENVALUES & \% VARIANCE & CUMULATIVE \% \\
\hline SPOS & 1 & 15.89 & 44.14 & 44.14 \\
& 2 & 1.82 & 5.05 & 49.19 \\
& 3 & 1.45 & 4.03 & 53.22 \\
& 4 & 1.31 & 3.63 & 56.85 \\
& 5 & 1.07 & 2.97 & 59.82 \\
& 6 & 1.01 & 2.81 & 62.63 \\
\hline
\end{tabular}

\section{RESULTS}

The results of this study involve four related sets of analyses. The first analysis was a factor analysis examining the structure of the SPOS, specifically employing oblique rotational methods to determine whether more than one factor might emerge if the structures were allowed to correlate. Secondly, the internal consistency reliabilities of the full and reduced versions of the SPOS (i.e. 36-item, 16-item, eight-item and three-item versions) were examined and compared. Thirdly, the intercorrelations of the factor scores and the four SPOS versions were calculated. Fourthly, in order to explore the convergent validity of the scales, the validity of the four versions was compared in relation to the three variables often used in conjunction with the SPOS, namely affective commitment, organisational participation and organisational communication.

Initially, the correlation matrix for the 36 items was examined. Bartlett's test of sphericity for the correlation matrix was statistically significant $\left[X^{2}(630)=5694.003, p=.000\right]$. The KaiserMeyer-Olkin (KMO) measure of sampling adequacy was 0.952, a very high value supporting the use of factor analysis with the matrix. The individual SPOS item responses were then subjected to a PAF analysis with direct oblimin rotation, $\delta=0$.

Six factors with eigenvalues greater than 1.0 were extracted by performing the PAF analysis on the correlations of the 36 items. The eigenvalues and variance accounted for by the initial factors are summarised in Table 1. Kaiser's rule is well known for producing too many factors (Stevens, 2002) and consequently, Cattell's (1966) scree plot was examined and clearly led to the conclusion that only one factor should be interpreted. The first eigenvalue was nearly nine times larger than the second, as the first factor extracted accounted for $44.14 \%$ of the variance and the second factor accounted for only $5.05 \%$ of the variance. A parallel analysis was performed (Horn, 1965) but produced somewhat ambiguous results regarding the second factor. Not only was the second factor of marginal size in terms of variance but it also correlated substantially with the first factor, $r=0.51$, and was not conceptually meaningful in terms of the item content. This evidence offers support for a unidimensional structure, even when an oblique rotation was employed. This conclusion is supportive of the original finding by Eisenberger et al. (1986) that the SPOS is unidimensional.

The items for the single factor were examined in terms of structure coefficients and communalities. The following items were the only two that failed to reach structure coefficients above 0.40: Item 30 had a structure coefficient equal to 0.38 ('If the organisation earned a greater profit, it would consider increasing my salary'), and item 36 had a structure coefficient equal to 0.34 ('My supervisors are proud that I am a part of this organisation'). The communalities ranged from 0.12 to 0.72 , with an average of 0.43 . There were 29 communalities with a value greater than 0.30 and 10 communalities with a value greater than 0.50 . Overall, these results seem to provide further support for the unidimensionality of the instrument. Before proceeding with the data analysis, factor scores for the SPOS were calculated for the sample on the single factor using the regression method.

Reliability analysis

A reliability analysis was conducted to examine the internal 
TABLE 2

Correlations between the POS factor score and POS total scores $(\mathrm{N}=266)$

\begin{tabular}{|c|c|c|c|c|c|c|c|c|}
\hline & & 1 & 2 & 3 & 4 & 5 & 6 & 7 \\
\hline 1. & $\begin{array}{l}\text { POS factor } \\
\text { score }\end{array}$ & 1.0 & & & & & & \\
\hline 2. & POS 36 items & 0.90 & 1.0 & & & & & \\
\hline 3. & POS 16 items & 0.96 & 0.97 & 1.0 & & & & \\
\hline 4. & POS eight items & 0.97 & 0.94 & 0.98 & 1.0 & & & \\
\hline 5. & POS three items & 0.86 & 0.85 & 0.88 & 0.88 & 1.0 & & \\
\hline 6. & $\begin{array}{l}\text { Affective } \\
\text { commitment }\end{array}$ & 0.58 & 0.60 & 0.61 & 0.60 & 0.58 & 1.0 & \\
\hline 7. & $\begin{array}{l}\text { Organisational } \\
\text { participation }\end{array}$ & 0.25 & 0.32 & 0.32 & 0.33 & 0.29 & 0.34 & 1.0 \\
\hline 8. & $\begin{array}{l}\text { Organisational } \\
\text { communication }\end{array}$ & 0.58 & 0.60 & 0.60 & 0.56 & 0.54 & 0.53 & 0.29 \\
\hline
\end{tabular}

All correlations are significant at $p<.001$

consistency reliability of the 36-item SPOS. The overall reliability coefficient (Cronbach's alpha) for the 36 items was very high with $\alpha=0.96$. Item-total correlations for the total scale ranged from 0.33 to 0.83 . The mean and median item-total correlations were 0.63 and 0.65 respectively. A reliability and item analysis of the scores obtained in the original study with the 36-item SPOS reported the internal consistency (Cronbach's alpha) at 0.97 , with item-total correlations ranging from 0.42 to 0.83 . The mean and median item-total correlations in the original study were 0.67 and 0.66 respectively.

In addition to examining the internal consistency of the 36-item SPOS, reliability analyses were conducted for each of the three shorter versions of the SPOS: the 16-item version, the eightitem version and the three-item version. Cronbach's alpha for the 16 items was $\alpha=0.95$, with item-total correlations ranging from 0.50 to 0.86 . The mean and median item-total correlations were 0.71 and 0.70 respectively. Cronbach's alpha for the eightitem version was $\alpha=0.93$, with item-total correlations ranging from 0.70 to 0.84 . The mean and median item-total correlations were 0.75 and 0.73 respectively. Lastly, Cronbach's alpha for the three-item version of the SPOS was $\alpha=0.81$, with item-total correlations ranging from 0.64 to 0.67 . The mean and median item-total correlations were 0.66 and 0.67 respectively.

\section{Correlations among factor scores and SPOS scale scores}

The correlation matrix of the single set of factor scores and the total scores for POS are presented in Table 2. As expected, large positive correlations were observed. The most notable pattern in Table 2 appears to be the somewhat smaller correlations of the three-item version of the SPOS with the factor scores and longer versions of the instrument. This is not unexpected given the lower reliability found for the three-item version in the preceding section.

\section{Convergent validity of the SPOS scales}

The relationships among the four forms of the SPOS and the selected organisational variables were examined by conducting a multiple regression analysis for each of the four versions of the SPOS separately. The total score for each version was regressed separately on a linear combination of three known correlates: affective commitment, organisational communication and organisational participation.

The 36-item SPOS total scores were predicted from a linear combination of affective commitment, organisational communication and organisational participation scores in a simultaneous equation. The regression equation with all the variables entered was statistically significant $[F(3,255)=$ $77.54, p<.001)$ and substantially meaningful, accounting for approximately $47.7 \%$ of the variance in the SPOS scores. This analysis was repeated, in turn, for the 16-item, eight-item and three-item versions of the SPOS. The regression equation for the 16-item SPOS with all the variables entered was statistically significant $[F(3,255)=81.27, p<0.001)$, accounting for approximately $48.9 \%$ of the variance in scale scores. Similarly, the regression equation for the eight-item scale with all the predictors entered was statistically significant $[F(3,255)=74.69$, $p<0.001$ ), accounting for approximately $46.8 \%$ of the variance scores. The regression equation for the three-item scale with all three predictors entered was also statistically significant $[F(3,255)=61.79, p<.001)$, accounting for approximately $42.1 \%$ of the variance in POS. The conclusion is that all four versions of the SPOS have significant convergent validity, relative to these three correlates. However, we do see a small relative decrease in the validity of the three-item version of the SPOS, at least relative to these three variables, almost $7 \%$ less shared variance than the 16-item version.

\section{DISCUSSION}

The results of the PAF factor analysis provide clear support for the unidimensionality of the 36-item SPOS. One large factor was found with 34 of the 36 items loading above the conventional criterion level of 0.40 . The remaining two items both had structure coefficients above 0.30 . The second factor consisted of only three items with loadings greater than 0.35 , and all three items loaded higher on the first factor. The correlation between the first and second factor $(r=0.51)$ also lends some credibility to the unidimensionality of the 36-item scale. The importance of the single-factor finding is that it occurred even when oblique rotation was applied, an issue that has not been addressed in previous research regarding the instrument. The finding of a single factor here both confirms and extends previous research claiming a one-factor solution for the instrument (Eisenberger et al., 1986; Kottke \& Sharafinski, 1988; Shore \& Tetrick, 1991).

The remaining three sets of analyses reveal several interesting results regarding the comparability of the 36-item, 16-item, eight-item and three-item versions of the SPOS that have been commonly applied in practice and research. Cronbach's alpha for these four versions were, respectively, $\alpha=0.96, \alpha=$ $0.95, \alpha=0.93$, and $\alpha=0.81$. The 15-point drop in the internal consistency of the three-item version is notable. This reduction in the estimate of internal consistency reliability has inherent implications for validity. The internal consistency for the 36item scale found with this sample is very close to the reliability estimate originally reported by Eisenberger et al. (1986). The 16item and eight-item versions of the instrument produce similar levels of internal consistency reliability. The reliability estimate for the three-item version is much lower. On this basis alone, one might recommend against using the three-item version when the eight-item version and the 16-item version perform better. This adds clarification to the statement by Rhoades and Eisenberger (2002) that the use of shorter versions does not appear problematic' (p. 699) and affirms a recommended caution with use of an extreme reduction in the number of SPOS items (Hellman, Fuqua \& Worley, 2006).

The correlations in Table 2 reveal several interesting coefficients relative to answering the question of whether or not the versions are interchangeable. First, the correlation between the eight-item and 16 -item versions $(r=0.98)$ indicates that these two scales could be used almost interchangeably. These two versions also reproduce the 36-item version extremely well with strong positive correlations between the 36 -item version and the eight-item $(r=0.94)$ and 16-item versions $(r=0.97)$, respectively. Based on these results one might conclude that either the eightitem or the 16-item version would be just as effective as the 36item version. However, the three-item version correlated less with the 36-item full version, $r=0.85$. Therefore, the three-item version shares about $16 \%$ less variance than did the eight-item version with the full 36-items.

Convergent validity with known correlates of perceived organisational support was expected given the reliabilities 
and the scale intercorrelations. When each of the four SPOS scales were predicted from a linear combination of the three known correlates of perceived organisational support (affective commitment, organisational communication and organisational participation) using a simultaneous multiple regression equation, the percentages of shared variance for the 36-item, 16-item, eight-item and three-item versions were, respectively, $48 \%, 49 \%, 47 \%$ and $42 \%$. Five to seven percent less of the threeitem scale was overlapping with the linear combination of the three correlates. The other three versions shared very similar proportions of variance with the correlates.

All of these results must be understood in the context of some limitations of the sample used here. Certainly, reliability is greatly affected by the sample characteristics, as are both regression and correlation statistics. The sample involved in this study was from a single organisation of a particular kind (a community college) and the sample was geographically specific to one area. While subjects were initially randomly selected from the organisation for participation, there was a significant non-response rate, and the differences between the respondents and non-respondents are not known. The generalisabilty of these results remains an empirical question. The general results reported here have, at least in part, been very similar to those reported elsewhere for the SPOS (Rhoades \& Eisenberger, 2002).

Results from the current analysis affirm that the SPOS is a unidimensional measure, even when the structures are allowed to correlate. The 36-item version of the SPOS is efficiently and efficaciously replaced by either the eight-item version or the 16item version. Given the strength of relationship of these two shorter versions found here, we might recommend the eightitem version just for its efficiency. The lower reliability and, consequently, lower validity in many applications of the threeitem version of the SPOS seem to point to the conclusion that the use of this version is not justifiable, especially in light of the availability of the superior eight-item scale.

\section{REFERENCES}

Allen, N.J., \& Meyer, J.P. (1990). The measurement and antecedents of affective, continuance and normative commitment to the organization. Journal of Occupational Psychology, 63(1), 1-18.

Allen, D.G., Shore, L.M., \& Griffeth, R.W. (2003). The role of perceived organisational support and supportive human resource practices in the turnover process. Journal of Management, 29(1), 99-118.

Aselage, J., \& Eisenberger, R. (2003). Perceived organisational support and psychological contracts: A theoretical integration. Journal of Organisational Behavior, 24(5), 491-509.

Bishop, J.W., Scott, K.D., \& Burroughs, S.M. (2000). Support, commitment, and employee outcomes in a team environment. Journal of Management, 26(6), 1113-1132.

Cattell, R.B. (1966). The scree test for the number of factors. Multivariate Behavioral Research, 1, 245-276.

Cropanzano, R., Howes, J.C., Grandey, A.A., \& Toth, P. (1997). The relationship of organisational politics and support to work behaviors, attitudes, and stress. Journal of Organisational Behavior, 18(2), 159-180.

Eisenberger, R. (2009). Perceived organizational support website. Retrieved April 17, 2009, from http://pos.psych.udel.edu/ publication_authors.asp

Eisenberger, R., Armeli, S., Rexwinkel, B., Lynch, P., \& Rhoades, L. (2001). Reciprocation of perceived organisational support. Journal of Applied Psychology, 86(1), 42-51.

Eisenberger, R., Cummings, J., Armeli, S., \& Lynch, P. (1997). Perceived organisational support, discretionary treatment, and job satisfaction. Journal of Applied Psychology, 82(5), 812820.

Eisenberger, R., Fasolo, P., \& Davis-LaMastro, V. (1990). Perceived organisational support and employee diligence, commitment, and innovation. Journal of Applied Psychology, 75(1), 51-59.

Eisenberger, R., Huntington, R., Hutchison, S., \& Sowa, D. (1986). Perceived organisational support. Journal of Applied Psychology, 71(3), 500-507.

Eisenberger, R., Rhoades, L., \& Cameron, J. (1999). Does pay for performance increase or decrease perceived selfdetermination and intrinsic motivation? Journal of Personality and Social Psychology, 77(5), 1026-1040.

Eisenberger, R., Stinglhamber, F., Vandenberghe, C., Sucharski, I.L., \& Rhoades, L. (2002). Perceived organisational support: Contributions to perceived organisational support and employee retention. Journal of Applied Psychology, 87(3), 565573.

Hellman, C.M., Fuqua, D.R., \& Worley, J.A. (2006). The effects of mean age and number of items on score reliability: A reliability generalization study on the survey of perceived organisational support. Educational $\mathcal{E}$ Psychological Measurement, 66(4), 631-642.

Horn, J.L. (1965). A rationale and test for the number of factors in factor analysis. Psychometrika, 30(2), 179-185.

Hutchison, S. (1997). Perceived organisational support: Further evidence of construct validity. Educational and Psychological Measurement, 57(6), 1025-1034.

Kahnweiler W.M., \& Thompson, M.A. (2000). Levels of desired, actual, and perceived control of employee involvement in decision making: An empirical investigation. Journal of Business and Psychology, 14(3), 407-427.

Kottke J.L., \& Sharafinski, C.E. (1988). Measuring perceived supervisory and organisational support. Educational and Psychological Measurement, 48(4), 1075-1079.

Levinson, H. (1965). Reciprocation: The relationship between man and organization. Administrative Science Quarterly, 9(4), 370-390.

Moorman, R.H., Blakely, G.L., \& Niehoff, B.P. (1998). Does organisational support mediate the relationship between procedural justice and organisational citizenship behavior? Academy of Management Journal, 41(3), 351-357.

Rhoades, L., \& Eisenberger, R. (2002). Perceived organisational support: A review of the literature. Journal of Applied Psychology, 87(4), 698-714.

Rhoades, L., Eisenberger, R., \& Armeli, S. (2001). Affective commitment to the organization: The contribution of perceived organisational support. Journal of Applied Psychology, 86(5), 825-836.

Seashore, S.E., Lawler, E.E., Mirvis, P.H., \& Camman, C. (1983). Assessing organizational change: A guide to methods, measures, and practices. New York: John Wiley and Sons.

Self, D.R., Holt, D.T., \& Schaninger, W.S. (2005). Work-group and organisational support: A test of distinct dimensions. Journal of Occupational and Organisational Psychology, 78(1), 133-140.

Settoon, R.P., Bennett, N., \& Liden, R.C. (1996). Social exchange in organizations: Perceived organisational support, leadermember exchange, and employee reciprocity. Journal of Applied Psychology, 81(3), 219-227.

Shore, L.M., \& Tetrick, L.E. (1991). A construct validity study of the survey of perceived organisational support. Journal of Applied Psychology, 76(5), 637-643.

Shore, L.M., \& Wayne, S.J. (1993). Commitment and employee behavior: Comparison of affective commitment and continuance commitment with perceived organisational support. Journal of Applied Psychology, 78(5), 774-780.

Sinclair, R.R., \& Tetrick, L.E. (1995). Social exchange and union commitment: A comparison of union instrumentality and union support perceptions. Journal of Organisational Behavior, 16(6), 669-680.

Stevens, J.P. (2002). Applied multivariate statistics for the social sciences. (4th edn.). Mahwah: Erlbaum.

Wayne, S.J., Shore, L.M., \& Liden, R.C. (1997). Perceived organisational support ad leader-member exchange: A social exchange perspective. Academy of Management, 40(1), 82-111. 